\title{
EMPLOYEE WELFARE PRACTICES AT INDIAN BATTERY INDUSTRY: AN EMPERICAL STUDY
}

\author{
Panthula Sree Sai Pavan ${ }^{1}$ \\ ${ }^{1}$ Research Scholar, \\ Dept. of Management, \\ Dravidian University, \\ Kuppam, A.P.
}

\author{
Prof.G.L.Narayanappa ${ }^{2}$ \\ ${ }^{2}$ Dean, \\ School of Commerce and Management, \\ Dravidian University, \\ Kuppam, A.P.
}

\section{ABC BATTERIES INDIA LTD}

$\mathrm{ABC}$ Batteries India Limited is one of the world class batteries manufacturing company established in the year 1985 and competing the global standards and competition in producing and marketing of batteries. It is the firm opinion of the 'ABC' Batteries Company that the standardization of quality of life by way of establishing the institution can extend evergreen accessibility to enhanced prospects and advantages to the mankind. By introducing the advanced engineering technology and scientific research, the ' $\mathrm{ABC}$ ' Batteries Company has entered into MOUs with global companies and making partnership ventures with world class leaders for want of transfer and sharing of technology and proficiency.

After establishing the industry as a private one subsequently in the year 1990 the industry was converted as public limited industry. The $\mathrm{ABC}$ Batteries Company has entered into MOU with an international industry of USA on partnership basis with a partnership percentage of 22 .

\section{IMPORTANCE OF EMPLOYEE WELFARE IN BATTERY INDUSTRY}

The concept of employee welfare would enhance the social behaviour of the employees in day to day corporate life in escorting the employees/workers from all kinds of humiliations such as (i) victimization; (ii) aggravation; and (iii) mobbing and so on. The workers/employees would expect to work in hassle free environment. Several researchers have carried out several studies in this area. But none of the studies have filled the fulpledged research gap in this area. In order to fill this gap in this area of research, this study is taken up to measure the degree of the involvement of the employer in implementing employee welfare.
Besides, the concept of employee welfare will also focus on how the organisations perceive their productive and non-productive tenures of experiences and their beliefs with their unions. This study also examines, whether the unions performing their organisations and whether the organisations are implementing the employee welfare programmes in the battery industry in accordance with the employee welfare provisions laid down in EMPLOYEES WELFARE ACT of the Government of India.

In the recent times, there has been a regeneration of importance in the employee welfare repercussions of contraption. Hence, the need of the hour is that the nature of relationship where the employee welfare programmes that the organization should implement for the benefit of their employees/workers. Securing highest salaries/wages for the employees/workers and safeguarding of the job security and extent of protection for the employees/workers should be the vital aspects of motto lies behind the practices employee welfare. ${ }^{(1)}$

The degree of the implementation of employee welfare programmes of any industry will play an enormous role in achieving its production targets. The battery industry has no exception for this. The full pledged co-operation and efforts of the employees/workers can be expected only when all the eligible employee welfare programmes are adopted for implementation intoto. Otherwise the organisations cannot think of achieving production $\operatorname{targets}^{(2)}$

It is obviously apparent that the concept of employee welfare and the is the vital parameter in the organisations to extract the maximum productivity from the employees. Recently, it is realized from the preceding decade that the sufficient welfare facilities are scientifically accomplishing inclination of the employees towards their job responsibility and 
eventually the about rate of employee turnover would be reduced in the organisations to the most extent. Even though, the number of welfare facilities are offered by the organisations for the employees, certain interruptions have been observed during the course of productivity. In order to identify the specific reasons for the coercive methods the researcher intentionally taken up this research work to dig out the authentic reasons for this course ${ }^{(3)}$

It is realized that the various welfare programmes extended by the organisations will immediate influence towards the productivity, psychological capability, physical health, foresight, attitude ad all round adoptability of the employees for the circumstances for achieving larger productivity. Further the prime purpose of the trade unionism is to augment the lives and careers of employees to extend them happiness and encouragement.

Anjugam et al (2007), specified that the social reluctance, and the marginal farm house holders join larger in the welfare schemes of selfhelp groups. Through this investigation it is found the rural self-help groups were operating cooperative milk dairies and dairy farms which include number of welfare programmes which will be useful for the rural masses. Author noticed that there is a huge gap of entrepreneurial skill sets among the members of the .self-help groups. ${ }^{(4)}$

PoonamSalaria, SumitSalaria,(2013), In this study the authors underlined that the employees in automobile industry are quite dissatisfied with the extramural welfare measures and on the flip side they are satisfied with intramural. However, the researcher noticed that the employees of the automobile sector have blended perception towards the welfare practices. Automobile industry is providing voluntary welfare services to their employees, which includes both intramural and extramural. Through this study the authors recommended that the employees are the crux for any organization, so that there should be given due importance in extending welfare measures. (5)

Tripathi(2013), in his study the author identified that the rural self-help groups have more potential to kick start their entrepreneurial journey in the space of diary and a allied activities inclusive of more number of welfare practices. Through this investigation it is found that the rural self-help groups were operating cooperative milk federation implementing number of welfare programmes for the welfare of dairy workers. The author noticed that there is a huge gap of entrepreneurial skill sets among the members of the .self-help groups. ${ }^{(6)}$

Purushothaman. G, Manjulapurushothaman. V and Krishnamurthy.K, (2014), In this research study they have recommended that there is deadly need of improving welfare practices in NEYCER INDIA LIMITED. It was noticed that the organizations not providing welfare practices and safety measures to the employees. It is going to imply negative attitude of the employer towards the employees, researchers who are advocated to the management of the organization to strengthen welfare and workplace safety of the employees. Otherwise it is going to hinge on the progress of the organization. ${ }^{(7)}$

Dr.UshaTiwari (2014), the author has carried out this study on the employee welfare facilities and its effect on the employees effectiveness of vindha telelinks ltd. The author observed that 66 percent of the employees are satisfied and this study triggers that the management have to much more focus on employee welfare schemes efficiency, till where it will impact on the quality of the work and efficiency of the work. It enhances the employee satisfaction levels and is going to impact on the overall performance of the employees. Hence, the author advised the organization to reframe the existing welfare measures of the scheme. ${ }^{(8)}$

Vikram Sing hand and RewariSandeepAggarwal (2014) in their study published in Journal of Commerce, Business and Management connects that the State governments safeguards the interest of employees and improves the working environment, equipment's of the employees through the labor legislation institutions. Socio economical parameters enrich the human issues in relation to an industry. However, there are certain problems with the labor laws which are not fullfldegly implemented by the employer. The bottom line of the study implies that even the workers were aware about the provisions of the factories Act. However, the employers are not employing for the welfare of the workers in most of the organizations in Haryana. Moreover, this study brought that the implication of awareness of employees welfare provisions completely rely upon the socio- economic environment of the industry. ${ }^{(9)}$

\section{SCOPE OF THE STUDY}

The scope of this study is confined to the employee welfare programmes of 'ABC' battery company only. The outcomes of this study cannot be comparable to any other similar industry or organisation.

\section{OBJECTIVES OF THE STUDY}

The distinct objectives of the study are:

i. To investigate the breathing tendencies of employee welfare programmes in $\mathrm{ABC}$ batteries industry;

ii. To assess the level of satisfaction/dissatisfaction of employees/workers towards in breathing tendencies of employee welfare programmes in ' $\mathrm{ABC}$ ' Batteries Company; 
iii. To scrutanise the reasons for the dissatisfaction of employee/worker respondents towards the breathing tendencies of employee welfare programmes in 'ABC' Batteries Company; and

iv.

To furnish the acceptable counter measures to flatten the dissatisfaction prevailed among the employee/workers towards the breathing tendencies of employee welfare programmes in 'ABC' Batteries Company.

\section{RESEARCH METHODOLOGY}

The methodology consists of data collection from primary as well as secondary sources. Through the survey method the first hand information was collected from 50 sample respondents from the study unit.

\section{SAMPLE DESIGN AND SIZE}

A purposive-cum-convenient sampling technique was followed and 50 respondents were chosen as sample respondents from the study unit.

\section{ANALYSIS OF THE DATA}

The information collected from the respondents was processed and tabulated scientifically and several statistical tools like (i) Independent sample t-test; (ii) Weighted mean scores; (iii) 'ANOVA' are calculated at appropriate levels and the inferences were drawn.

\section{THE LIMITATIONS}

1. The study is confined to only one battery industry located in India;

2. The size of the sample is $\mathbf{5 0}$ only where the number is meagre.

3.

\section{RESEARCH FINDINGS}

1. The present employee welfare programmes are not at all augmenting the performance of employees and the employees are not able to undertake and monitor the job responsibilities in an organized manner. Further, the employees also are not able to possess the required skills for selfmotivation and for team work $(56.00 \%)$.

2. The present employee welfare programmes are negatively influencing towards the performance of employees which weakens the total productive activity of the organization $(52.00 \%)$.

3. The present schemes of employee welfare are not accomplishing the societal needs of the employees and hence the productivity of the organization is not at all increased $(44.00 \%)$.
4. Improper safety welfare measures are prevailed in the organization. Proper uniform as prescribed in the standing orders and high quality safety shoes are not supplied by the organization. The margin of space between one worker and other worker is also flimsy and hence the circulation of free air is blocked $(38.00 \%)$.

5. The impact of present employee welfare schemes on the productivity of the organization is insignificant and playing non-imperative role on the efficiency of the employees and as well as on the organization $(36.00 \%)$.

\section{SUGGESTIONS}

1. It is proposed to design the employee welfare programmes on more rational and scientific lines which can be useful to augment the employee's performance suited to their present profession. The proposed welfare programmes should make the employees self-reliant and should be capable of independently monitor their jobresponsibilities and posses the slaills which can be useful for self-motivation of the employees to actively participate into their job responsibilities.

2. The proposed employee welfare programmes should positively motivate the employees towards their performance and in turn such positive motivation should make the workers to put their sustained efforts for maximizing the productivity and profits.

3. While designing the employee welfare programmes, the professional ethics of the employees should be taught to them which can be useful for them to discharge their corporate social responsibilities. So that the social needs of the can be recognized and fulfilled by the organization and the productivity of the organization can be enhanced.

4. Proper and scientific measures such i) fixing of fire-exchequers; ii) distribution of safety mosques and gloves; iii) distribution of prescribed uniform; and iv) distribution of high quality safety shoes should be implemented with immediate effect. Further, a technical space committee consisting of a space engineer and H.R. manager should frequently visit the plant and arrange the space gap between one work and another worker at least one meter in the operational area of the plant for want of circulation of the free air in the working area of the plant.

5. While preparing the mew employee welfare programmes certain internal connection should be incorporated between the 
proposed welfare programme and increase of the productivity of the organization. So that when the proposed employee welfare programmes are conferred on the employees, automatically the productivity of the organization would also be increased and the imperative role can be played by the organization towards the efficiency of the employees.

\section{REFERENCES}

1. Josephine Seapel Moeti-Lysson: "Effectiveness of Trade Unions in promoting employee relations in organisation", Research gate, Jan-2011, pp.56-57

2. Purshothaman.G, Manjual purshothaman and Krishanmurthy.K: "A study on employee welfare measures in Neycer India Ltd”, Journal of Human Resource Management and Development, Vol.4, June 2014, p.23.

3. Subhasish Chaterji, Medha Wadhva and Dhrashana Patel: "A study on employee welfare and its impact on their performance at private hospitals and its research centre-cross sectional descriptive study", IJRAR, 2018, Vol.5, issue.12, p.504.

4. Anjugam, M. and Ramasamy, C. Determinants of Women"s participation in Self-Help Group led micro finance programme in TamilNadu. Agricultural Economics Research Review, 2007, 20(2), 2007.

5. PoonamSalaria, SumitSalaria Employee welfare measures in Auto sector, International Journal of Business and Management Invention ISSN (Online): 2319 - 8028, ISSN (Print): 2319 $801 X$ www.ijbmi.org Volume 2 Issue $3 \|$ March. 2013\| PP.66-74.

6. Tripathi, V.K.Corporate -Self Help Group linkages for rural development, Self Help Groups, Kurukshetra -A Journal on Rural Development, 61, pp. 5-8, 2013.

7. Purushothaman. G, Manjulapurushothaman. V and Krishnamurthy. K, a study on employees welfare measures in neycerindia ltd, Journal of Human Resource Management and Development (JHRMD) ISSN $(P): \quad 2277-4742 ; \quad \operatorname{ISSN}(E)$ : Applied Vol. 4, Issue 1, Jun 2014, 23-28

8. Dr.UshaTiwari, a study on employee welfare facilities and its impact on employees efficiency at vindhatelelinks ltd. rewa (m.p.) india, Abhinav International Monthly Refereed Journal of Research in Management \& Technology, Volume 3, Issue 11 (November, 2014) Online ISSN-23200073.

9. Vikram Sing hand RewariSandeepAggarwal (2014),Employees awareness towards the Welfare Provisions of Factories Act 1948 and its Implementation in the state of Haryana" punished in Journal of Commerce, Business and Management. 